\title{
PENYELESAIAN PERSAMAAN DIFERENSIAL PARSIAL FOKKER-PLANCK DENGAN METODE GARIS
}

\author{
Siti Muyassaroh \\ Mahasiswa Jurusan Matematika Fakultas Sains dan Teknologi UIN Maulana Malik Ibrahim Malang \\ e-mail: muy.sms@gmail.com
}

\begin{abstract}
ABSTRAK
Persamaan Fokker-Planck merupakan persamaan diferensial parsial yang menggambarkan fungsi distribusi partikel dalam suatu sistem yang berisi banyak partikel yang saling bertumbukan. Digunakan metode garis untuk menyelesaikan solusi numerik pada persamaan Fokker-Planck. Metode ini merepresentasikan bentuk persamaan diferensial parsial ke dalam bentuk sistem persamaan diferensial biasa yang ekuivalen pada bentuk persamaan diferensial parsialnya. langkah pertama yang dilakukan untuk menyelesaikan persamaan Fokker-Planck dengan metode garis yaitu mengganti turunan ruang dengan metode beda hingga pusat, sehingga diperoleh bentuk sistem persamaan diferensial biasa. Langkah kedua yaitu menyelesaikan sistem persamaan diferensial biasa yang telah diperoleh pada langkah pertama dengan metode penyelesaian yang berlaku pada persamaan diferensial biasa yaitu metode Runga-Kutta. Hasil solusi numerik dengan metode garis kemudian dibandingkan dengan solusi eksak menghasilkan galat yang sangat kecil atau mendekati nol. Sehingga dapat disimpulkan bahwa metode garis merupakan metode yang baik untuk menyelesaikan persamaan Fokker-Planck.
\end{abstract}

Kata kunci: persamaan Fokker-Planck, metode garis, metode Runga-Kutta.

ABSTRACT
Fokker-Planck equation is partially differential equation that describe distribution function of particles on system contain many particles that collide each other. The method of lines is used to solve numerical solution of Fokker-Planck equation. This method represents form of partially differential equation into the form of ordinary differential equation that equivalent to the form of its partially differential equation. The first step to solve Fokker-Planck equation using line method is replacing spatial derivative with center finite difference, in order to obtain system of ordinary differential equation. The second step is solving the system of ordinary differential equation that have been obtained in the first step using the method of lines using the solving method that used at ordinary differential equation, that is Runga-Kutta method of fourth order. Then numerical solution obtained by using the method of lines is compared to the exact solution and produce error that very small or tend to zero. Therefore, it can be concluded that the method of lines is good method for solving Fokker-Planck equation.

Keywords: Fokker-Planck equation, Line method, Runge-Kutta method.

\section{PENDAHULUAN}

\begin{abstract}
Persamaan Fokker-Planck merupakan persamaan yang menggambarkan fungsi distribusi partikel dalam suatu sistem yang berisi banyak partikel yang saling bertumbukan. Persamaan ini berisi komponen difusi partikel dan interaksi antar partikel (Palupi, 2010).
\end{abstract} Bentuk umum persamaan Fokker-Planck adalah:

$$
v_{t}(x, t)=-A v_{x}(x, t)+\frac{1}{2} B v_{x x}(x, t)
$$

dengan $v$ merupakan fungsi distribusi partikel, $A$ disebut sebagai koefisien apung (drift coefficient) dan $B$ disebut sebagai koefisien diffusi (Zauderer, 2006). Persamaan Fokker-Planck termasuk persamaan diferensial parsial karena mengandung turunan parsial, yaitu turunan dengan dua variabel bebas $x$ dan $t$.

Salah satu metode untuk menyelesaikan persamaan diferensial parsial adalah dengan metode garis (method of lines). Metode garis merupakan metode beda hingga khusus yang menghasilkan solusi numerik yang mendekati solusi sebenarnya. Ide dasar metode ini yaitu mengubah bentuk persamaan diferensial parsial ke dalam bentuk persamaan diferensial biasa.

Metode garis telah banyak diterapkan pada beberapa permasalahan persamaan diferensial parsial. Beberapa penelitian terdahulu yang membahas metode garis antara lain yaitu membahas solusi numerik persamaan Kortewegde Vries dengan metode garis (Ozdes \& Aksan, 2006). Penelitian lain membahas penerapan 
metode garis pada persamaan Laplace (Sadiku \& Obiozor, 1997).

Metode garis memiliki beberapa keunggulan antara lain metode ini sangat efisien dalam perhitungan karena menghasilkan solusi yang akurat dengan sedikit waktu yang ditempuh. Selain itu metode ini juga mudah dalam menentukan kestabilannya dengan memisahkan antara variabel ruang dan waktu (Sadiku \& Obiozor, 1997).

\section{KAJIAN TEORI}

\section{Persamaan Diferensial Parsial Fokker-Planck}

Persamaan Fokker-Planck merupakan persamaan yang menggambarkan fungsi distribusi partikel dalam suatu sistem yang berisi banyak partikel yang saling bertumbukan (Palupi, 2010). Persamaan ini pertama kali dikenalkan oleh Fokker dan Planck. Beberapa penerapan persamaan Fokker-Planck antara lain pada gerakan tidak menentu partikel kecil yang direndam dalam suatu cairan, fluktuasi intensitas sinar laser, dan distribusi kecepatan partikel cairan dalam aliran turbulen. Secara umum persamaan Fokker-Planck dapat diaplikasikan pada sistem keseimbangan maupun ketakseimbangan (Frank, 2004).

Awal terbentuknya persamaan nonlinier Fokker-Planck merupakan akibat terjadinya tumbukan antara partikel, sehingga mengalami perubahan arah gerak secara acak (Brownian Motion). Partikel yang disebut sebagai partikel Brownian tersebut mengalami proses diffusi. Gerakan partikel bersifat acak dan gerakan partikel tidak dipengaruhi oleh gerakan partikel sebelumnya (Palupi, 2010).

Persamaan Fokker-Planck termasuk persamaan diferensial parsial (PDP) karena persamaan ini menggambarkan laju perubahan terhadap dua variabel bebas yaitu waktu dan jarak (ruang). Jika dilihat dari persamaan (1), maka persamaan Fokker-Planck merupakan PDP orde satu terhadap variabel bebas $t$ dan orde dua terhadap variabel bebas $x$. Persamaan FokkerPlanck merupakan PDP tipe parabolik.

\section{Metode Beda Hingga Persamaan Fokker- Planck}

Untuk persamaan Fokker-Planck yang mengandung variabel $x$ dan $t$, perkiraan beda hingga dilakukan dengan membuat jaringan titik hitungan pada bidang $x-t$ yang dibagi dalam sejumlah pias dengan interval ruang dan waktu adalah $\Delta x$ dan $\Delta t$. Turunan parsial pada setiap titik grid didekati dari nilai-nilai tetangga dengan menggunakan deret Taylor. Berikut merupakan turunan pertama dan kedua variabel $x$ dengan metode beda hingga pusat:

$$
\begin{aligned}
& v_{x}\left(x_{i}, t_{n}\right) \approx \frac{v_{i+1}^{n}-v_{i}^{n}}{\Delta x} \\
& v_{x x}\left(x_{i}, t_{n}\right) \approx \frac{v_{i+1}^{n}-2 v_{i}^{n}+v_{i-1}^{n}}{\Delta x^{2}}
\end{aligned}
$$

Sedangkan untuk turunan pada variabel $t$ dilakukan dengan cara yang sama seperti di atas.

\section{Metode Garis}

Metode garis merupakan salah satu dari metode numerik yang paling efisien untuk menyelesaikan persamaan diferensial parsial. Metode ini banyak diaplikasikan pada beberapa masalah di bidang fisika teori. Metode garis pertama kali dikenalkan oleh matematikawan asal Jerman bernama Erich Rothe pada tahun 1930 (Pregla, 2008).

Ide dasar metode garis adalah mengganti turunan ruang (nilai batas) pada persamaan diferensial parsial dengan pendekatan aljabar. Setelah ini dilakukan, turunan ruang tidak lagi dinyatakan secara eksplisit dalam variabel bebas ruang. Dengan demikian, hanya ada variabel nilai awal saja artinya dengan adanya satu variabel bebas yang tersisa maka diperoleh sistem persamaan diferensial biasa (PDB) yang mendekati persamaan diferensial parsial yang asli. Kemudian selanjutnya adalah merumuskan pendekatan sistem persamaan diferensial biasa. Setelah ini dilakukan maka bisa diterapkan beberapa pendekatan untuk nilai awal persamaan diferensial biasa guna menghitung solusi numerik dari persamaan diferensial parsial (Hamdi, Schiesser, \& Griffiths, 2009).

\section{Metode Runga-Kutta}

Penyelesaian PDB dengan metode deret Taylor tidak praktis, karena metode tersebut membutuhkan perhitungan turunan $f(x, y)$. Disamping itu, tidak semua fungsi mudah dihitung turunannya, terutama bagi fungsi yang bentuknya rumit. Oleh karena itu metode RungaKutta merupakan alternatif dari metode deret Taylor yang memberikan ketelitian hasil yang lebih besar dan tidak memerlukan turunan fungsi (Triatmodjo, 2002).

Bentuk umum metode Runga-Kutta:

$$
v_{r+1}=v_{r}+h \theta\left(x_{r}, v_{r}, h\right)
$$

dengan $\theta\left(x_{r}, y_{r}, h\right)$ adalah fungsi pertambahan yang menggambarkan kemiringan pada interval.

Ada beberapa tipe metode Runga-Kutta yaitu metode Runga-Kutta orde satu, dua, tiga dan empat. Metode Runga-Kutta orde empat banyak digunakan karena mempunyai ketelitian 
yang lebih tinggi (Chapra \& Canale, 2002). Berikut merupakan bentuk metode Runga-Kutta orde empat:

$$
v_{r+1}=v_{r}+\frac{1}{6}\left(k_{1}+2 k_{2}+2 k_{3}+k_{4}\right) h
$$

dengan:

$k_{1}=f\left(x_{r}, v_{r}\right)$

$k_{2}=f\left(x_{r}+\frac{1}{2} h, v_{r}+\frac{1}{2} k_{1}\right)$

$k_{3}=f\left(x_{r}+\frac{1}{2} h, v_{r}+\frac{1}{2} k_{2}\right)$

$k_{4}=f\left(x_{r}+h, v_{r}+k_{3}\right)$

\section{PEMBAHASAN}

\section{Penerapan Metode Garis pada Penyelesaian Persamaan Fokker-Planck}

Ide dasar metode garis terdiri dari dua langkah, pertama mengganti turunan ruang dengan menggunakan metode beda hingga sehingga diperoleh sistem persamaan diferensial biasa. Kemudian menyelesaikan sistem persamaan diferensial biasa yang sudah diperoleh dengan menggunakan metode penyelesaian pada persamaan diferensial biasa, seperti metode Euler, metode Runga-Kutta dan lain-lain. Metode ini dinamakan metode garis karena solusi ditentukan pada setiap garis $x=x_{i}$ dimana daerah solusi dibagi menjadi beberapa garis lurus yang sejajar dengan sumbu-y pada batas tertentu (Sadiku \& Obiozor, 1997).

Berikut merupakan model persamaan yang akan diselesaikan dengan metode garis:

$$
v_{t}-x e^{3 t} v_{x x}-v_{x}=2 x e^{2 t}-e^{2 t}
$$

Dengan nilai awal yang diberikan yaitu $v(x, 0)=$ $x$, untuk $x \in(0,1)$ dan nilai batas $v(0, t)=0$, $v(1, t)=e^{2 t}$. Daerah solusi dibatasi pada $0 \leq x \leq$ 1 dan $0 \leq t \leq 1$ (Hussain \& Alwan, 2013).

Langkah pertama yang harus dilakukan pada metode garis adalah mengganti turunan ruang pada persamaan diferensial parsial dengan menggunakan metode beda hingga pusat. Transformasi beda pusat untuk turunan pertama dan kedua variabel ruang:

$$
\begin{aligned}
& v_{x}\left(x_{i}, t_{n}\right) \approx \frac{v_{i+1}^{n}-v_{i}^{n}}{\Delta x} \\
& v_{x x}\left(x_{i}, t_{n}\right) \approx \frac{v_{i+1}^{n}-2 v_{i}^{n}+v_{i-1}^{n}}{\Delta x^{2}}
\end{aligned}
$$

subtitusi pada persamaan (6) sehingga akan diperoleh bentuk berikut:

$$
\begin{aligned}
\frac{\partial v}{\partial t}\left(x_{i}, t_{n}\right)= & x_{i} e^{3 t_{n}}\left(\frac{v_{i+1}^{n}-2 v_{i}^{n}+v_{i-1}^{n}}{\Delta x^{2}}\right)+ \\
& \frac{v_{i+1}^{n}-v_{i-1}^{n}}{2 \Delta x}+2 x_{i} e^{2 t_{n}}-e^{2 t_{n}}
\end{aligned}
$$

Ketika turunan variabel ruang sudah diganti dengan beda hingga, maka turunan ruang tersebut tidak lagi dinyatakan secara eksplisit dalam variabel bebas ruang. Sehingga tersisa variabel nilai awal saja yaitu variabel $t$. Dengan demikian karena tersisa satu variabel bebas saja maka diperoleh sistem persamaan diferensial biasa (PDB) yang mendekati PDP aslinya (Hamdi, Schiesser, \& Griffiths, 2009). Maka persamaan diferensial parsial di atas berubah menjadi bentuk persamaan diferensial biasa berikut:

$$
\begin{aligned}
\frac{d v}{d t}\left(x_{i}, t_{n}\right)= & x_{i} e^{3 t_{n}}\left(\frac{v_{i+1}^{n}-2 v_{i}^{n}+v_{i-1}^{n}}{\Delta x^{2}}\right)+ \\
& \frac{v_{i+1}^{n}-v_{i-1}^{n}}{2 \Delta x}+2 x_{i} e^{2 t_{n}}-e^{2 t_{n}}
\end{aligned}
$$

Jika dipilih $\Delta x=0,25$ maka daerah solusi terdiri dari $x_{i}$, dengan $i=0,1,2,3,4$ dan $\Delta t=0,01$ atau $n=0,1,2, \cdots, 101$. Sehingga akan diperoleh sistem persamaan diferensial biasa sebagai berikut:

$\frac{d v_{0}^{n}}{d t}=x_{0} e^{3 t_{n}}\left(\frac{v_{1}^{n}-2 v_{0}^{n}+v_{-1}^{n}}{\Delta x^{2}}\right)+\frac{v_{1}^{n}-v_{-1}^{n}}{2 \Delta x}+2 x_{0} e^{2 t_{n}}-$

$e^{2 t_{n}}$

$\frac{d v_{1}^{n}}{d t}=x_{1} e^{3 t_{n}}\left(\frac{v_{2}^{n}-2 v_{1}^{n}+v_{0}^{n}}{\Delta x^{2}}\right)+\frac{v_{2}^{n}-v_{0}^{n}}{2 \Delta x}+2 x_{1} e^{2 t_{n}}-$

$e^{2 t_{n}}$

$\frac{d v_{2}^{n}}{d t}=x_{2} e^{3 t_{n}}\left(\frac{v_{3}^{n}-2 v_{2}^{n}+v_{1}^{n}}{\Delta x^{2}}\right)+\frac{v_{3}^{n}-v_{1}^{n}}{2 \Delta x}+2 x_{2} e^{2 t_{n}}-$

$e^{2 t_{n}}$

$\frac{d v_{3}^{n}}{d t}=x_{3} e^{3 t_{n}}\left(\frac{v_{4}^{n}-2 v_{3}^{n}+v_{2}^{n}}{\Delta x^{2}}\right)+\frac{v_{4}^{n}-v_{2}^{n}}{2 \Delta x}+2 x_{3} e^{2 t_{n}}-$

$e^{2 t_{n}}$

$\frac{d v_{4}^{n}}{d t}=x_{4} e^{3 t_{n}}\left(\frac{v_{5}^{n}-2 v_{4}^{n}+v_{3}^{n}}{\Delta x^{2}}\right)+\frac{v_{5}^{n}-v_{3}^{n}}{2 \Delta x}+2 x_{4} e^{2 t_{n}}-$

$e^{2 t_{n}}$

Langkah kedua setelah diperoleh sistem PDB adalah menyelesaikan PDB tersebut dengan metode Runga-Kutta orde empat. Bentuk umum metode Runga-Kutta orde empat yaitu sebagaimana pada persamaan (5). Hasil perhitungan solusi metode garis digambarkan dalam tabel berikut.

Tabel 1. Solusi Metode Garis Persamaan Fokker-Planck (6)

\begin{tabular}{|l|c|c|c|c|c|c|}
\hline Iterasi & $\boldsymbol{t}$ & $\boldsymbol{x}_{\mathbf{0}}$ & $\boldsymbol{x}_{\mathbf{1}}$ & $\boldsymbol{x}_{\mathbf{2}}$ & $\boldsymbol{x}_{\mathbf{3}}$ & $\boldsymbol{x}_{\mathbf{4}}$ \\
\hline 1 & 0 & 0 & 0,25 & 0,5 & 0,75 & 1 \\
\hline 2 & 0,01 & 0 & 0,2549 & 0,5100 & 0,7651 & 1,0202 \\
\hline 3 & 0,02 & 0 & 0,2600 & 0,5202 & 0,7804 & 1,0408 \\
\hline 4 & 0,03 & 0 & 0,2652 & 0,5306 & 0,7961 & 1,0618 \\
\hline 5 & 0,04 & 0 & 0,2704 & 0,5412 & 0,8121 & 1,0833 \\
\hline$\vdots$ & $\vdots$ & $\vdots$ & $\vdots$ & $\vdots$ & $\vdots$ & $\vdots$ \\
\hline 101 & 1 & 0 & 1,8091 & 3,9021 & 5,1894 & 7,3891 \\
\hline
\end{tabular}




\section{Perbandingan Solusi Analitik dan Solusi Numerik Metode Garis pada Persamaan Fokker-Planck}

Solusi eksak (analitik) persamaan Fokker-Planck (6) adalah sebagai berikut (Hussain \& Alwan, 2013):

$$
v(x, t)=x e^{2 t}
$$

Bertujuan untuk menunjukkan bahwa solusi dengan metode garis adalah mendekati solusi analitik maka keduanya digambarkan dalam bentuk plot. Solusi analitik persamaan Fokker-Planck (6) sebagai berikut:

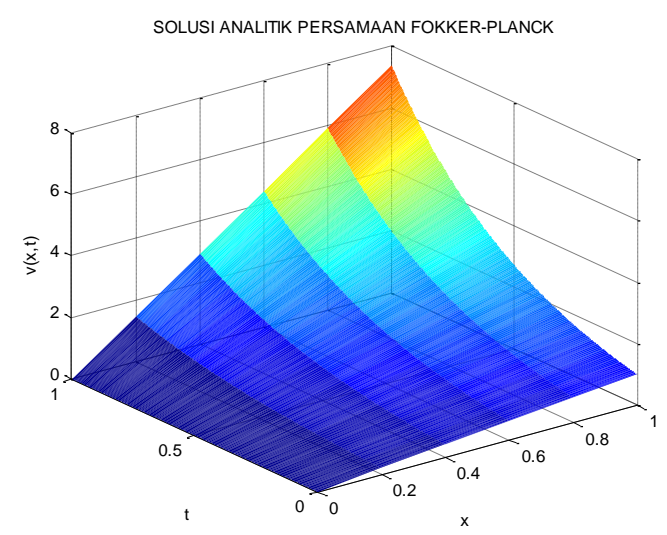

Gambar 1. Solusi analitik persamaan Fokker-Planck (6)

Sedangkan plot solusi numerik dengan metode garis sebagai berikut:

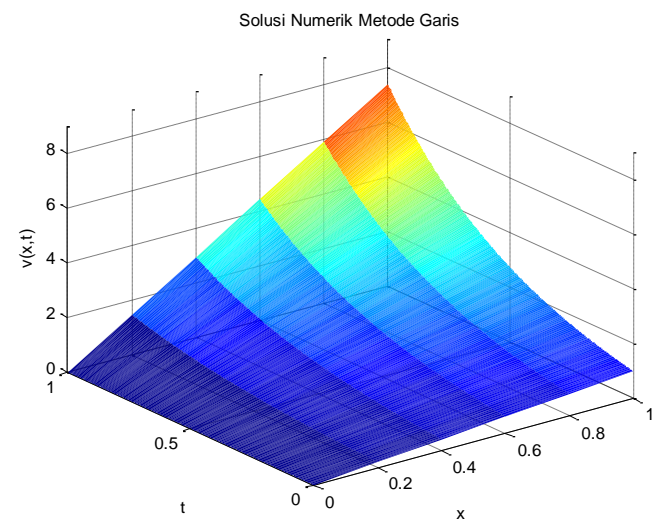

Gambar 2. Solusi numerik persamaan Fokker-Planck (6)

Penyelesaian secara numerik hanya menghasilkan nilai yang mendekati pada solusi analitiknya. Bertujuan untuk mengetahui besarnya error metode garis terhadap solusi eksaknya, dapat dilakukan dengan menghitung selisih antara nilai eksak dan nilai pendekatan dengan metode garis. Besarnya error digambarkan pada tabel berikut.

Tabel 2. Perbandingan Solusi Numerik dan Analitik

\begin{tabular}{|c|c|c|c|c|}
\hline $\boldsymbol{x}$ & $\boldsymbol{t}$ & $\begin{array}{c}\text { Solusi } \\
\text { Numerik }\end{array}$ & $\begin{array}{c}\text { Solusi } \\
\text { Eksak }\end{array}$ & $\begin{array}{c}\text { Nilai } \\
\text { error }\end{array}$ \\
\hline
\end{tabular}

\begin{tabular}{|c|c|c|c|c|}
\hline & & $\boldsymbol{v}(\boldsymbol{x}, \boldsymbol{t})$ & $\boldsymbol{v}(\boldsymbol{x}, \boldsymbol{t})$ & \\
\hline 0,25 & 0,01 & 0,2549 & 0,2551 & 0,0002 \\
\hline 0,25 & 0,02 & 0,2600 & 0,2602 & 0,0002 \\
\hline 0,25 & 0,03 & 0,2652 & 0,2655 & 0,0003 \\
\hline 0,25 & 0,04 & 0,2704 & 0,2708 & 0,0004 \\
\hline 0,25 & 0,05 & 0,2758 & 0,2763 & 0,0005 \\
\hline$\vdots$ & $\vdots$ & $\vdots$ & $\vdots$ & $\vdots$ \\
\hline 0,75 & 1 & 5,1894 & 5,5418 & 0,3524 \\
\hline
\end{tabular}

Sedangkan untuk mengetahui error pemotongan yang dihasilkan oleh persamaan Fokker-Planck, dilakukan diskritisasi dengan metode beda hingga pusat, sehingga terbentuk skema berikut:

$\frac{v_{i}^{n+1}-v_{i}^{n-1}}{2 \Delta t}+A\left(\frac{v_{i+1}^{n}-2 v_{i}^{n}+v_{i-1}^{n}}{\Delta x^{2}}\right)-\frac{1}{2} B\left(\frac{v_{i+1}^{n}-v_{i-1}^{n}}{2 \Delta x}\right)$

$=f(x, t)$

Konsistensi dapat dicari dengan menggunakan ekspansi deret Taylor pada masing-masing sukunya. Kemudian suku-suku sejenis dikelompokkan, sehingga diperoleh persamaan berikut:

$$
\begin{aligned}
& \left.\left(v_{t}+A v_{x}-\frac{B}{2} v_{x x}\right)\right|_{i} ^{n}+\left.\frac{1}{6} \Delta t^{2} v_{t t t}\right|_{i} ^{n}+ \\
& \left.\Delta x^{2}\left(\frac{A}{6} v_{x x x}-\frac{B}{24} v_{x x x x}\right)\right|_{i} ^{n}+\left.\frac{1}{120} \Delta t^{4} v_{t t t t t}\right|_{i} ^{n}+ \\
& \left.\Delta x^{4}\left(\frac{A}{120} v_{x x x x x}-\cdots\right)\right|_{i} ^{n}=f(x, t)
\end{aligned}
$$

Dari persamaan (12) dapat diketahui bahwa error pemotongan yang dihasilkan mempunyai orde dua yaitu $\mathcal{O}\left(\Delta t^{2}, \Delta x^{2}\right)$. Persamaan (12) dikatakan konsisten jika

$$
\begin{gathered}
\left.\lim _{(\Delta t, \Delta x) \rightarrow 0} \frac{1}{6} \Delta t^{2} v_{t t t}\right|_{i} ^{n}+\left.\Delta x^{2}\left(\frac{A}{6} v_{x x x}-\frac{B}{24} v_{x x x x}\right)\right|_{i} ^{n} \\
=0
\end{gathered}
$$

Jika $\Delta t$ dan $\Delta x$ sangat kecil maka jumlah dari limit tersebut akan semakin kecil, karena berapapun nilai $v_{t t t}, v_{x x x}, v_{x x x x}$ jika dikalikan dengan nilai dari $\Delta t$ dan $\Delta x$ akan ikut mengecil. Error pemotongan yang dihasilkan akan menuju nol untuk $\Delta t \rightarrow 0$ dan $\Delta x \rightarrow 0$.

\section{Interpretasi Hasil}

Metode garis merupakan metode numerik yang lebih akurat dibandingkan metode beda hingga biasa karena menghasilkan solusi yang akurat dengan waktu perhitungan yang dibutuhkan lebih efisien. Penyelesaian dengan metode garis terdiri dari dua tahap, yaitu mengganti turunan variabel ruang dengan metode beda hingga sehingga diperoleh sistem PDB yang mendekati bentuk PDP asli, kemudian langkah kedua yaitu menyelesaikan sistem PDB 
dengan metode penyelesaian PDB. Bentuk metode beda hingga yang digunakan yaitu beda hingga pusat karena titik-titik yang dihitung dipengaruhi oleh titik-titik disekitarnya sehingga beda hingga pusat dianggap lebih baik daripada beda hingga maju dan mundur. Kemudian penyelesaian PDB menggunakan metode RungaKutta orde empat karena metode ini mempunyai ketelitian yang lebih tinggi Bertujuan untuk mengetahui perbandingan solusi analitik dan solusi metode garis, maka keduanya digambarkan dalam bentuk plot di atas. Hasil plot menunjukkan bahwa solusi analitik dan solusi metode garis pada persamaan (6) hampir sama atau dapat dikatakan bahwa solusi metode garis mendekati solusi analitiknya. Hasil perhitungan menghasilkan nilai error yang sangat kecil menunjukkan bahwa solusi metode garis hampir mendekati solusi analitik. Error pemotongan pada persamaan FokkerPlanck dilihat dengan cara ekspansi deret Taylor pada tiap suku-sukunya sehingga dihasilkan error pemotongan yang mempunyai orde dua yaitu $\mathcal{O}\left(\Delta t^{2}, \Delta x^{2}\right)$.

\section{PENUTUP}

Berdasarkan pembahasan di atas, diperoleh kesimpulan bahwa langkah pertama untuk menyelesaikan persamaan Fokker-Planck dengan metode garis adalah mengganti turunan variabel ruang dengan metode beda hingga, sehingga diperoleh bentuk sistem persamaan diferensial biasa. Langkah kedua yaitu menyelesaikan sistem PDB yang terbentuk dengan metode Runga-Kutta orde empat. Solusi yang dihasilkan dengan metode garis mendekati nilai eksaknya. Jadi dapat disimpulkan bahwa metode garis merupakan metode yang baik untuk menyelesaikan permasalahan solusi numerik pada persamaan Fokker-Planck.

\section{DAFTAR PUSTAKA}

[1] Chapra, S.C. dan Canale, R.P. (2002). Numerical Methods for Engineers with
Software and Programing Applications. Fourth Edition. New York: The Mc Graw-Hill Companies, Inc.

[2] Frank, T. (2004). Nonlinear Fokker-Planck Equation. Munster: Springer-Berlin.

[3] Hamdi S., William E. Schiesser, Graham W. Griffiths. (2009). Method of Lines. Scholarpedia, 5.

[4] Hussain, E. d. (2013). The Finite Volume Method for Solving Systems of Non-linear Initial-Boundary Value Problems for PDE's. Applied Mathematical Science, 1737-1755.

[5] Ozdes A. dan Aksan E.N. (2006). The Method of Lines Solution of the Korteweg-de Vries Equation for Small Times. Int. J. Contemp. Math. Science, 639-650.

[6] Palupi, D. (2010). Persamaan Fokker-Planck dan Aplikasinya dalam Astrofisika. Jurnal Berkala Fisika, A1-A6.

[7] Pregla, R. (2008). Analysis of Elegtromagnetic Fields and Waves: The Method of Lines. British: John Wiley \& Sons, Ltd.

[8] Sadiku, M.N.O dan Obiozor, C.N. (1997). A Simple Introduction to the Method of Lines . International Journal of Electrical Engineering Education, 282-296.

[9] Triatmodjo, B. (2002). Metode Numerik Dilengkapi dengan Program Komputer. Yogyakarta: Beta Offset.

[10] Zauderer, E. (2006). Partial Differential Equations of Applied Mathematich. New York: Wiley-Interscience. 